\title{
Prolactin potentiates insulin-stimulated leptin expression and release from differentiated brown adipocytes
}

\author{
S Viengchareun, H Bouzinba-Segard ${ }^{1}$, J-P Laigneau², M-C Zennaro, P A Kelly ${ }^{1}$, \\ A Bado ${ }^{2}$, $M$ Lombès and $\mathbf{N}$ Binart ${ }^{1}$ \\ INSERM U478, Institut Fédératif de Recherche Claude Bernard, Faculté de Médecine Xavier Bichat, 16 rue Henri Huchard, 75018 Paris, France \\ 1INSERM U584, Faculté de Médecine Necker-Enfants Malades, 156 rue de Vaugirard, 75730 Paris Cedex 15, France \\ 2INSERM U410, Institut Fédératif de Recherche Claude Bernard, Faculté de Médecine Xavier Bichat, 16 rue Henri Huchard, 75018 Paris, France
}

(Requests for offprints should be addressed to N Binart; Email: binart@ necker.fr)

\begin{abstract}
The pituitary hormone prolactin (PRL) exerts pleiotropic effects, which are mediated by a membrane receptor (PRLR) present in numerous cell types including adipocytes. Brown adipose tissue (BAT) expresses uncoupling proteins (UCPs), involved in thermogenesis, but also secretes leptin, a key hormone involved in the control of body weight. To investigate PRL effects on BAT, we used the T37i brown adipose cell line, and demonstrated that PRLRs are expressed as a function of cell differentiation. Addition of PRL leads to activation of the JAK/STAT and MAP kinase signaling pathways, demonstrating that PRLRs are functional in these cells. Basal and catecholamine-induced UCP1 expression were not affected by PRL. However, PRL combined with insulin significantly increases leptin expression and release, indicating that $P R L$ potentiates the stimulatory effect of insulin as revealed by the recruitment of insulin receptor substrates and the activation of phosphatidylinositol 3-kinase. To explore the in vivo physiological relevance of PRL action in BAT, we showed that leptin content was significantly increased in BAT of PRLR-null mice compared with wild-type mice, highlighting the involvement of PRL in the leptin secretion process. This study provides the first evidence for a functional link between PRL and energy balance via a cross-talk between insulin and PRL signaling pathways in brown adipocytes.
\end{abstract}

Journal of Molecular Endocrinology (2004) 33, 679-691

\section{Introduction}

Prolactin (PRL) is a $23 \mathrm{kDa}$ peptide synthesized by the anterior pituitary and to a lesser extent by numerous extrapituitary tissues. This member of the cytokine family influences various physiological processes including the regulation of mammary gland development and lactation, reproduction, osmoregulation and lipid metabolism (Goffin et al. 2002). These multiple actions are mediated via the binding of PRL to its receptor (PRLR), a member of the class I cytokine receptor superfamily, leading to activation of the JAK/STAT signaling pathway (Bole-Feysot et al. 1998). PRLR expression is detected at widely varying levels in almost all tissues, both adult and fetal. Interestingly, Royster et al. (1995) reported by in situ hybridization analysis an unexpectedly high level of PRLR transcripts in brown adipose tissue (BAT) of fetal rats.

BAT is a highly specialized tissue, which clearly differs from the energy-storing white adipose tissue. Indeed, BAT is characterized by its thermogenic function because it has the ability to dissipate energy and to provide heat. This results from the activity of the uncoupling protein 1 (UCP1) which translocates protons through the inner membrane of mitochondria, uncouples oxidative phosphorylation and bypasses the last enzymatic step of the respiratory chain, ATP synthase (Ricquier \& Bouillaud 2000). BAT plays therefore a major role in the regulation of body temperature, especially in small animals such as mice or rats. Moreover, we have recently shown that brown adipocytes are also endocrine cells able to secrete leptin (Buyse et al. 
2001) and other adipocytokines such as resistin and adiponectin, two adipocyte-specific secretory factors involved in glucose and lipid metabolism (Viengchareun et al. 2002). Despite high levels of PRLR transcripts in BAT, the precise role of PRL in this tissue is still unclear. Indeed, a recent study reported that infusion of PRL to pregnant rats induced an increase in UCP1 protein expression in the BAT of fetuses (Budge et al. 2002), while the same authors reported that PRL caused a reduction in UCP1 abundance only in females and not in males (Pearce et al. 2003). These observations suggested a potential involvement of PRL in thermoregulation.

With the aim of better understanding the specific role of PRL in BAT, we used both the brown adipocyte T37i cell line (Zennaro et al. 1998) and the PRLR knockout mouse model (Ormandy et al. 1997). T37i cells were derived from a hibernoma developed in a transgenic mouse in which the expression of SV40 large T antigen was placed under the control of the proximal promoter of the human mineralocorticoid receptor gene. These cells are capable of differentiating into mature brown adipocytes upon insulin and triiodothyronine (T3) exposure as assessed by their ability to display multilocular intracytoplasmic lipid droplets and by the occurrence of specific adipogenic gene activation (Penfornis et al. 2000). Importantly, expression of UCP1, but also of leptin, resistin and adiponectin were demonstrated in this cell line (Zennaro et al. 1998, Buyse et al. 2001, Viengchareun et al. 2002).

Null mutation of the PRLR has mainly highlighted its essential role in reproduction and mammary gland development and suggested that most of its other reported target tissues are presumably modulated by, rather than strictly dependent on PRL. Among the metabolic actions of PRL (Bole-Feysot et al. 1998), its role in lipid metabolism remains poorly understood. Progressive reduction in body weight associated with a reduction in total abdominal fat mass and in leptin concentrations was observed in null females (Freemark et al. 2001); this is in agreement with the increase of serum leptin concentrations observed in PRL transgenic females (Ling \& Billig 2001). The T37i cell line and the PRLR knockout model therefore represent suitable experimental systems to explore the function of PRL in BAT.

\section{Materials and methods}

\section{Cell culture, hormones and drugs}

T37i cells were cultured in a complete medium composed of DMEM/Ham's F12, 10\% fetal calf serum, $2 \mathrm{mM}$ glutamine, $100 \mathrm{IU} / \mathrm{ml}$ penicillin, $100 \mu \mathrm{g} / \mathrm{ml}$ streptomycin and $20 \mathrm{mM}$ HEPES and were grown at $37^{\circ} \mathrm{C}$ in a humidified atmosphere with $5 \% \mathrm{CO}_{2}$. All products were purchased from Invitrogen. Differentiation into mature brown adipocytes was achieved by incubating subconfluent undifferentiated $\mathrm{T} 37 \mathrm{i}$ cells with complete medium supplemented with $2 \mathrm{nM}$ T3 (Sigma) and $20 \mathrm{nM}$ insulin (Invitrogen) for 7 days (Zennaro et al. 1998). Before each hormonal treatment, T37i cells were subsequently cultured for $18 \mathrm{~h}$ in the same medium without any serum named 'minimum medium'. Human PRL was produced by recombinant technology then purified as described previously (Goffin et al. 1996) and kindly provided by Dr V Griffin (INSERM U584, Paris, France). All experiments were performed with T37i cells between passages 10 and 20. Actinomycin D, all-trans retinoic acid and isoproterenol were purchased from Sigma.

\section{PRLR knockout mice}

All experimental designs and procedures were in agreement with the guidelines of the animal ethics committee of the Ministère de l'Agriculture (France). Wild-type, PRLR ${ }^{+/-}$and PRLR ${ }^{-/-}$ mice on a pure 129 genetic background were generated by heterozygous crossbreeding (Ormandy et al. 1997). PGR analysis of tail DNA determined the genotypes of the offspring as described previously (Binart et al. 2000).

\section{Ribonuclease protection assay (RPA)}

PRLR cDNA was digested with HindIII and BamHI to generate a $390 \mathrm{bp}$ fragment corresponding to exon 10 of the long-form PRLR gene, which was thereafter ligated into pBluescript KS. $O b$-PGEMT easy plasmid was generated as previously described (Buyse et al. 2001). In vitro synthesis of riboprobes was achieved using the PRLR-pBluescript KS or the Ob-PGEMT easy plasmids linearized by HindIII and NcoI respectively. PRLR $\alpha-{ }^{32}$ P-labeled antisense riboprobe was synthesized with T7 RNA polymerase (Promega) 
whereas $O b$ antisense riboprobe was synthesized with Sp6. The mouse $\beta$-actin riboprobe, used as an internal control, was synthesized with T7 RNA polymerase after digestion of the $\beta$-actin-pGEM3 plasmid by Bsu36I. RPAs were performed as previously described (Buyse et al. 2001). Fifty micrograms of total RNA, isolated from T37i cells or BAT using TRIZOL reagent (Invitrogen), were hybridized with $4 \times 10^{5}$ c.p.m. PRLR riboprobe or $4 \times 10^{5}$ c.p.m. $\mathrm{Ob}$ riboprobe, together with $4 \times 10^{4}$ c.p.m. $\beta$-actin riboprobe. Protected fragments were electrophoresed on a $6 \%$ polyacrylamide/urea gel. Gels were dried and fixed in $10 \%$ acetic acid. Radioactivity was counted overnight with an InstantImager (Packard, Meriden, CT, USA) followed by an autoradiography. Results are expressed in arbitrary units and correspond to the ratio between PRLR- or $O b$-specific counts vs $\beta$-actin signal. Unprotected PRLR riboprobe migrated at 450 bases with a protected fragment migrating at 390 bases whereas unprotected $O b$ riboprobe migrated at 305 bases with a protected fragment migrating at 260 bases. Unprotected $\beta$-actin riboprobe migrated at 158 bases with a protected fragment migrating at 137 bases.

\section{Northern blot analysis}

Fifteen micrograms of total RNA were analyzed by Northern blotting as previously described (Maniatis et al. 1982). $\alpha-{ }^{32}$ P-labeled probes were synthesized by random priming (Megaprime; Amersham Biotech) of cDNA encoding UCP1 and GAPDH. Membranes were subjected to autoradiography and specific hybridization signals were quantified using an InstantImager. Results are expressed in arbitrary units corresponding to the ratio of specific counts for UCP1 vs GAPDH signal.

\section{Immunoprecipitation and Western blot analysis}

COS cells were transiently transfected with a mouse PRLR cDNA (kindly provided by D Linzer, Northwestern University, Evanston, IL, USA) using lipofectamine plus reagent (Life Technologies, Groningen, The Netherlands). Cells were subsequently lysed at $4{ }^{\circ} \mathrm{C}$ in lysis buffer (see below). Lysates were clarified by centrifugation at $15000 \boldsymbol{g}$ for $30 \mathrm{~min}$ and the supernatants were transferred to a fresh tube. After protein content determination (Bradford Method; Bio-Rad), equal amounts of proteins were immunoprecipitated at $4{ }^{\circ} \mathrm{C}$ with the anti-PRLRl antibody (kindly provided by $\mathrm{F}$ Talamantes, University of California, Santa Cruz, CA, USA), and the immune complexes were collected on Protein A Sepharose. After washing, immunoprecipitates were reduced for $5 \mathrm{~min}$ at $95{ }^{\circ} \mathrm{C}$ in Laemmli buffer and analyzed by SDS-PAGE.

\section{Studies of the activation of JAK/STAT, MAP kinase and insulin signaling pathways}

Differentiated cells starved for $18 \mathrm{~h}$ in minimum medium, were stimulated with $100 \mathrm{ng} / \mathrm{ml} \mathrm{PRL}$, $20 \mathrm{nM}$ insulin or with both during 0-60 min; cells were washed twice with ice-cold PBS and lysed in ice with $10 \mathrm{mM}$ Tris-HCl pH 7·6, $5 \mathrm{mM}$ EDTA, $150 \mathrm{mM} \mathrm{NaCl}, 30 \mathrm{mM}$ sodium pyrophosphate, $50 \mathrm{mM}$ sodium fluoride, $1 \mathrm{mM}$ sodium orthovanadate, 10\% glycerol and 2\% Nonidet P40 (NP40) supplemented, just before use, with $1 \mu \mathrm{M}$ pepstatin A, $50 \mu \mathrm{M}$ leupeptin, $1 \mu \mathrm{M}$ aprotinin and $1 \mathrm{mM}$ phenylmethylsulfonylfluoride (PMSF). Lysates were sonicated and cleared from insoluble material by centrifugation. Protein concentrations were determined by the modified Bradford method and $500 \mu \mathrm{g}$ total protein were immunoprecipitated overnight at $4{ }^{\circ} \mathrm{C}$ with Protein A Sepharose (Amersham) and the respective antibodies: rabbit polyclonal anti-JAK2 (06-255) from Upstate Biotechnology (Lake Placid, NY, USA), rabbit polyclonal anti-STAT5 (G17), rabbit polyclonal anti-STAT3 (C-20) from Santa Cruz Biotechnology Inc. (Santa Cruz, CA, USA), anti-insulin receptor substrate proteins (anti-IRS)-1 (Upstate Biotechnology), anti-IRS-2 (Upstate Biotechnology), or anti-phosphatidylinositol 3-kinase (PI 3-kinase) (p85 antibodies; Upstate Biotechnology). The immunoprecipitate was reduced in Laemmli buffer and an 8\% acrylamide SDS-PAGE was performed. After electrophoretic transfer of proteins to nitrocellulose membranes, they were blocked (TBS/0.1\% Tween 20/5\% BSA) then incubated with monoclonal anti-phosphotyrosine (clone 4 G10) from Upstate Biotechnology diluted 1/5000 in TBS/0 $1 \%$ Tween 20/1\% BSA, washed with TBS/0.1\% Tween 20, then incubated with the secondary antibody, anti-mouse IgG peroxidase-linked (Amersham), washed, developed with ECL Western blotting detection reagent (Amersham) and exposed to film (X-ray film AX; Konica, Roissy, France). Blots were stripped by 
30 min incubation at $50{ }^{\circ} \mathrm{C}$ in $62.5 \mathrm{mM}$ Tris $\mathrm{pH}$ $6 \cdot 8,2 \%$ SDS, $100 \mathrm{mM}$ 2-mercaptoethanol, washed with TBS/0 $1 \%$ Tween 20 and incubated with anti-JAK2, anti-STAT5 or anti-STAT3 respectively and anti-rabbit IgG peroxidase-linked (Amersham) as secondary antibody. Direct Western blots were performed on $40 \mu \mathrm{g}$ total protein extracts revealed with polyclonal anti-MAP kinase (ERK1/2) and monoclonal anti-MAP kinase phosphotyrosines (ERK1/2-pY) clone 12D4 (Upstate Biotechnology). IRS-1 (anti-IRS-1), IRS-2 (anti-IRS-2), PI 3-kinase (anti-PI 3-kinase p85 antibodies) were from Upstate Biotechnology. Quantifications were performed using an EDAS120 system (Kodak digital imaging system) and software (Grosdemouge et al. 2003). The intensity of phosphorylated proteins was normalized to that of the unphosphorylated form of the same protein. Results are expressed in arbitrary units.

\section{Leptin RIA}

Extraction of total proteins from T37i cells was performed at $4{ }^{\circ} \mathrm{C}$ in RIPA buffer $(50 \mathrm{mM}$ Tris, $1 \%$ Triton $\mathrm{X}-100,0 \cdot 5 \%$ deoxycholic acid, $0 \cdot 1 \% \mathrm{SDS}$, $50 \mathrm{mM} \mathrm{NaF}, 150 \mathrm{mM} \mathrm{NaCl} \mathrm{pH} \mathrm{7.4)} \mathrm{containing}$ $0.1 \mathrm{mg} / \mathrm{ml}$ PMSF, $100 \mu \mathrm{M}$ benzamidine and $100 \mathrm{mM}$ sodium orthovanadate as protease inhibitors. The lysate was centrifuged at $15000 \mathrm{~g}$ for $20 \mathrm{~min}$. The amount of protein was quantified using the Bradford method. Leptin content in aliquots of culture medium or in cell lysate was quantified using the mouse leptin RIA kit from Linco Research, Inc. (St Charles, MO, USA) with a detection limit of $0 \cdot 2 \mathrm{ng} / \mathrm{ml}$. BAT from 2-week-old wild-type and PRLR knockout mice was removed and weighed. Tissues were homogenized using a glass-Teflon homogenizer in PBS buffer containing $0.1 \mathrm{mg} / \mathrm{ml}$ PMSF and $200 \mathrm{IU}$ aprotinin. The homogenates were centrifuged at $10000 \boldsymbol{g}$ for $10 \mathrm{~min}$ and the supernatants were collected and used for leptin determination by RIA.

\section{Statistical analysis}

Data are expressed as means \pm S.E.M. and \pm S.D. One-way ANOVA, followed by the NewmanKeuls multiple range test or $t$-test was used to determine significant differences among groups, they were performed using the computer software InStat version 2.01 for Macintosh (GraphPad
Software, San Diego, CA, USA). Statistical significance are indicated at $P$ values $<0 \cdot 05,<0 \cdot 01$ and $<0 \cdot 001$.

\section{Results}

\section{Identification and characterization of PRLRs in differentiated T37i cells}

We first examined the presence of PRLR mRNA in the T37i cells as a function of differentiation state (Fig. 1A and B). RPA analyses indicated that PRLR expression progressively increased during brown adipocyte differentiation and reached a maximal level at day 6 then decreased afterwards. Importantly, PRLR transcripts were not detected by RT-PGR in undifferentiated T37i cells (data not shown), suggesting that PRLR expression occurs only during the process of adipocyte differentiation. We next examined the stability of PRLR transcripts by RPA (Fig. 1G) and showed that PRLR transcript levels rapidly declined after actinomycin $\mathrm{D}$ incubation with a calculated half-life of approximately $5 \cdot 5 \mathrm{~h}$ (Fig. 1D), indicating that PRLR expression is presumably under a strict transcriptional control. To further investigate PRLR expression, differentiated T37i cells were treated with insulin or T3, two hormones important in brown adipocyte differentiation (Fig. 1E). Quantitative results indicated that the level of PRLR transcripts was increased 2- to 3-fold by insulin or T3 (Fig. 1F), suggesting that both hormones could stimulate PRLR gene transcription.

The presence of PRLRs was also studied in T37i cells by Western blot analysis using an antibody directed against the amino terminus of the PRLR, which allowed the detection of a $90 \mathrm{kDa}$ band in COS cells transiently transfected with mouse PRLR cDNA (Fig. 2A). As shown in Fig. 2B, differentiated T37i cells expressed PRLR in contrast to undifferentiated cells, confirming the results obtained at the mRNA level.

\section{Activation of JAK/STAT and MAP kinase pathways by PRL}

Because the phosphorylation-dependent activation of JAK/STAT is a major transduction pathway for PRL signaling, we investigated the JAK2 and STAT phosphorylation in cellular extracts of differentiated cells in response to PRL. As shown in 
Fig. 3, the phosphorylated form of JAK2 was maximal after $5 \mathrm{~min}$ of PRL stimulation and decreased thereafter. PRL treatment also induced strong tyrosine phosphorylation of STAT5, which declined after $15 \mathrm{~min}$. Interestingly, PRL also led to the phosphorylation of STAT3, indicating that in this cell model, PRL is able to transduce hormonal signal through activation of both the STAT5 and the STAT3 pathways.

Since PRL was also shown to stimulate cell proliferation by activating the MAP kinase pathway, we examined the presence of phosphorylated forms of p42/p44 MAP kinase (ERK1/2) in differentiated T37i cell extracts in response to PRL (Fig. 3). A clear increase in phosphorylated ERK1/2 kinases was detected in PRL-stimulated cells with a maximal activation level after $5 \mathrm{~min}$, which decreased afterwards. Taken together, these results demonstrate that PRL is able to activate both JAK/STAT and MAP kinase pathways, indicating that PRLRs are functional in brown adipocytes but it questions on the target genes of PRL in BAT.

\section{Effects of PRL on brown adipocyte gene expression}

Because brown adipocytes are mainly involved in thermoregulation via modulation of UCP1 expression, we investigated the effect of PRL on the expression of UCP1 transcripts in differentiated T37i cells. Figure 4 shows that PRL alone did not modulate UCP1 gene expression nor alter the isoproterenol-stimulated UCP1 transcript levels in differentiated T37i cells. Similar results were obtained after retinoic acid stimulation (data not shown). These results indicate that UCP1 transcription is presumably not directly regulated by PRL.

We have previously shown that leptin, the $O b$ gene product, is expressed and secreted by differentiated T37i cells and have further demonstrated that insulin is the major stimulator of $\mathrm{Ob}$ gene transcription and leptin secretion (Buyse et al. 2001). These findings suggest that the brown adipocyte-secreted leptin could be a potential target for PRL action. We therefore investigated whether PRL could modify $O b$ gene expression in T37i cells. Differentiated cells were serum-starved for $18 \mathrm{~h}$ and then treated with insulin, PRL or a combination of both hormones. Insulin was able to stimulate by 2-fold $O b$ transcript levels whereas PRL alone had no effect on $O b$ gene expression. Surprisingly, PRL combined with insulin significantly increased (2-fold) the insulin-stimulated leptin mRNA levels (Fig. 5A), consistent with a synergistic mechanism. We also examined by RIA the leptin concentration in the supernatant of differentiated T37i cells in response to various hormonal treatments (Fig. 5B). Overnight incubation with insulin strongly increased leptin secretion from a basal level of $0 \cdot 22 \pm 0 \cdot 03$ to $1 \cdot 38 \pm 0 \cdot 18 \mathrm{ng} / \mathrm{ml}$. PRL alone had no effect on basal leptin secretion $(0 \cdot 30 \pm 0 \cdot 14 \mathrm{ng} /$ $\mathrm{ml})$. However, when combined with insulin, the leptin concentration in the medium reached $1.98 \pm 0.15 \mathrm{ng} / \mathrm{ml}$, a value significantly higher than that achieved by insulin exposure, indicating that PRL potentiates the stimulatory effect of insulin on leptin release. It is worth noting that pretreatment of differentiated T37i cells with PRL before insulin incubation did not result in a cooperative increase in leptin content (data not shown), suggesting that potentiation only occurs when brown adipocytes are simultaneously exposed to insulin and PRL.

\section{Activation of the insulin signaling pathway is enhanced by PRL}

Insulin stimulates tyrosine phosphorylation of proteins that are composed of IRS-1, -2 and -3 . To determine the molecular events underlying this potentiating mechanism, we studied the activation of IRS in differentiated T37i cells in response to PRL, insulin or both (Fig. 6). Equal amounts of cell lysate proteins were immunoprecipitated with either the anti-IRS-1 or the anti-IRS-2 antibodies, and analyzed by Western blotting with the anti-phospho Tyr (pY) antibody. Figure 6A and B show the tyrosine phosphorylation of the IRS proteins induced by insulin, whereas PRL alone fails to activate phosphorylation of IRS-1 or -2 . Interestingly, the combination of PRL and insulin resulted in an enhanced activation of IRS- 1 and -2 . Beside the increase in tyrosine-phosphorylated IRS-1 and -2, an important molecular mass shift of IRS proteins was observed after insulin and PRL treatment as compared with insulin alone. This finding could be due to an increase in IRS phosphorylation status on tyrosine and possibly on serine/threonine residues. Altogether, these results suggest that both IRS- 1 and -2 are involved in the insulin signaling in T37i cells and that PRL potentiates insulin action. In addition, the 
A
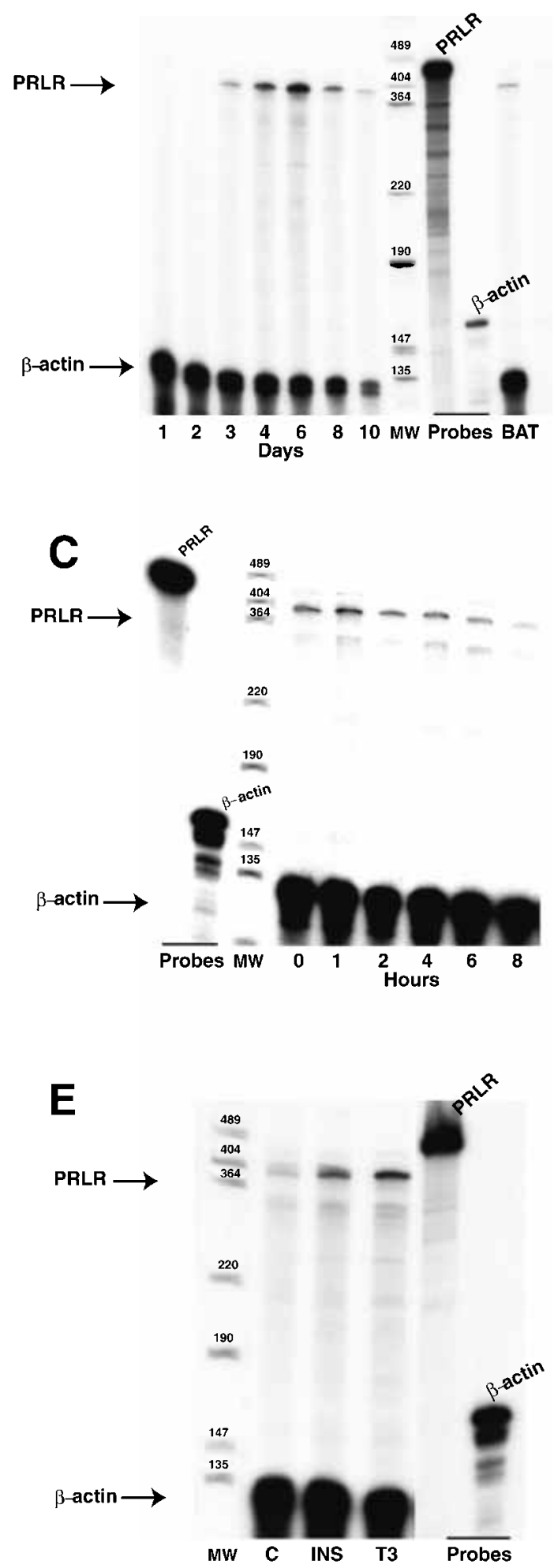

B
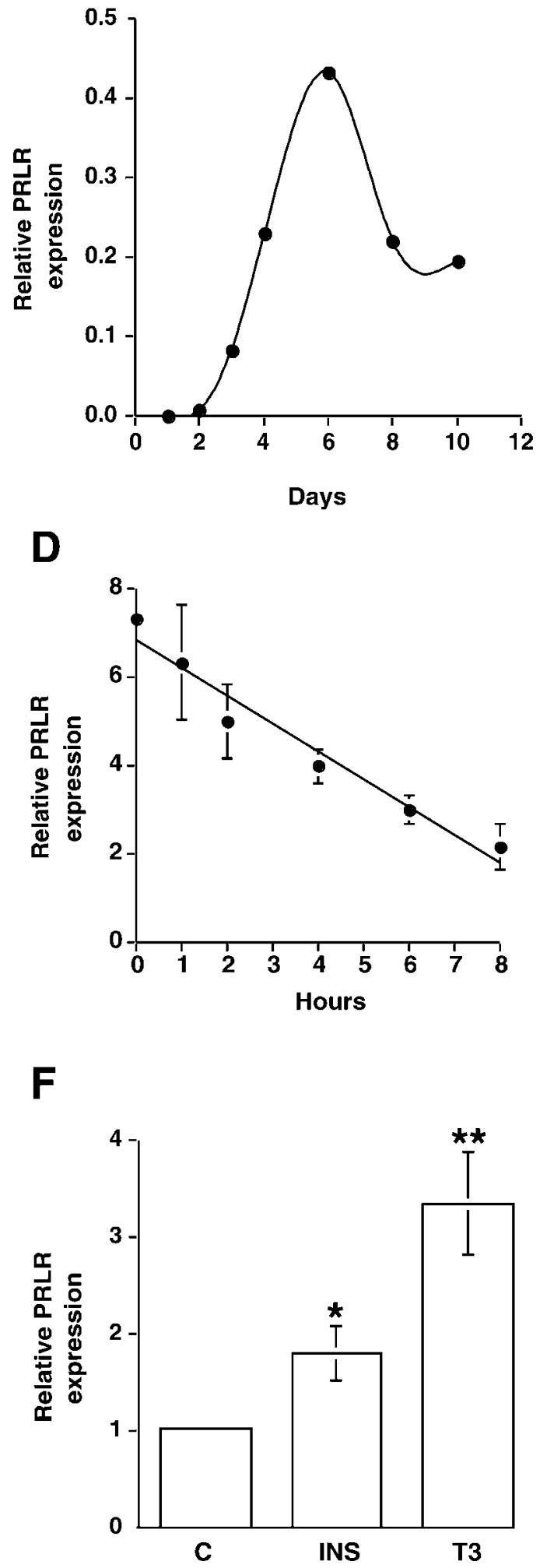
A

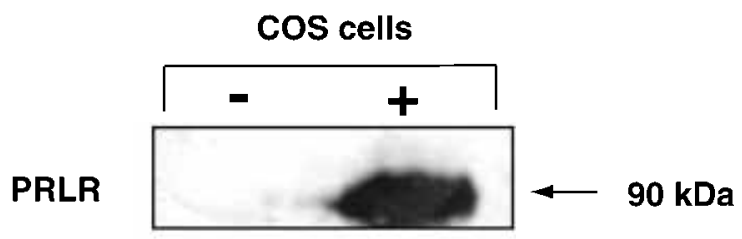

B

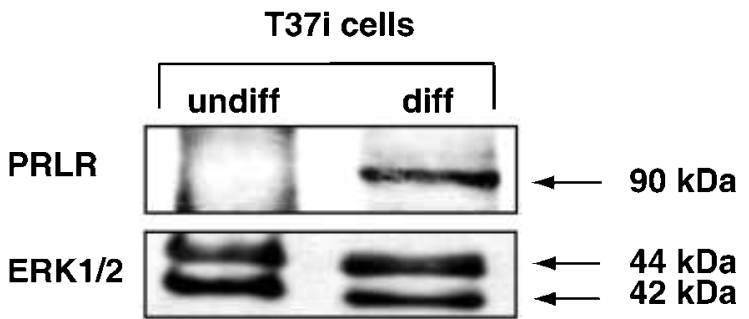

Figure 2 Immunoprecipitation and Western blot analysis of PRLRs in T37i cells. (A) Thirty micrograms of protein from mock (-)- or PRLR (+)-transfected COS cells were immunoprecipitated with anti-PRLR antibody and subjected to SDS-PAGE followed by Western blotting. A band of $\sim 90 \mathrm{kDa}$ (arrow) is detected only in transfected cells. (B) Forty micrograms of protein from undifferentiated (Undiff) or differentiated (Diff) T37i cells, were loaded on SDS-PAGE followed by direct Western blot analysis performed with anti-PRLR antibody and anti-MAP kinase (ERK1/2) as a loading control.

membranes were stripped and incubated with a PI 3-kinase antibody confirming that tyrosine phosphorylated IRS-1 and -2 are associated with the p85a subunit of PI 3-kinase and that the combination of both hormones enhanced the binding of p85 $\alpha$ to both IRS- 1 and -2 , greater than did insulin alone (data not shown). To further demonstrate the balance in the association between
IRS-1/2 and p85a subunit of PI 3-kinase in these cells after stimulation by the hormones, lysates were immunoprecipitated with the anti-p85 $\alpha$ antibody, then immune complexes were subjected to Western blot analysis. As shown in Fig. 6C, we observed a substantial increase in the amount of both IRS-1 and -2 in the anti-p85 $\alpha$ immunoprecipitates upon combined treatment with insulin and PRL. Moreover, not only IRS-1 but also IRS-3 was shown to play a major role in insulin-induced activation of PI 3-kinase in adipocytes. Indeed, we observed that the combined treatment of both insulin and PRL was also able to induce tyrosine phosphorylation of IRS-3 and its association with PI 3-kinase (Fig. 6C).

\section{Analysis of UCP1 and leptin expression in BAT of PRLR-null mice}

As a first attempt to understand the physiological relevance of PRL actions in BAT, we investigated UCP1 expression in the BAT of 2-week-old PRLR knockout animals at both messenger and protein level. No differences were observed among the PRLR genotypes $(+/+,+/-,-/-)$ suggesting that the null mutation of PRLR did not directly affect the expression of UCP1 transcripts and protein in vivo (data not shown).

Since PRL was shown to potentiate the stimulatory effect of insulin on leptin expression and release from differentiated T37i cells (see Fig. 5), we analyzed $O b$ gene expression in the BAT of wild-type, $\mathrm{PRLR}^{+\prime-}$ and PRLR-null mice and showed that the level of $O b$ transcripts was not significantly different in any of the three genotypes, suggesting that $O b$ gene expression was not altered by the null mutation of PRLRs (Fig. 7A). However, leptin content measured by RIA was $2 \cdot 7$-fold

Figure 1 Expression and hormonal regulation of PRLR transcripts in T37i cells. (A, B) Expression of PRLR mRNA during T37i cell differentiation. This illustrates one representative experiment of four RPAs performed. T37i cells were cultured in the complete medium supplemented with $2 \mathrm{nM} \mathrm{T3}$ and $20 \mathrm{nM}$ insulin (INS). From day 1 to 10, total RNA was extracted and processed for RPA using specific probes for PRLR and $\beta$-actin (A). Signals were quantified by Instantlmager and expressed as the ratio of PRLR/ $\beta$-actin specific counts (B). BAT: brown adipose tissue; MW: molecular weight. (C, D) Determination of PRLR transcript half-life in T37i cells. At day 6 of the differentiation process, T37i cells were incubated for various times with $0.4 \mu \mathrm{M}$ actinomycin D; total RNA was processed for RPA using specific probes for PRLR and $\beta$-actin (C). Signals were quantified as described above. Results represent means \pm S.D. of three independent determinations. The linear regression of the equation was $y=-0.626 x+6 \cdot 802$, $\left(r^{2}=0.959\right)$. The estimated half-life value for the PRLR transcript was $5.5 \mathrm{~h}(\mathrm{D})$. (E, F) Hormonal regulation of PRLR gene expression. Differentiated T37i cells were incubated in minimum medium for $18 \mathrm{~h}$ without or with $20 \mathrm{nM}$ insulin or $100 \mathrm{nM}$ T3 and total RNA was processed for RPA (E). Control cells corresponded to the mock-treated cells. Results represent means \pm S.E.M. of ten independent determinations. ${ }^{\star} P<0.05 ;{ }^{\star \star} P<0.01$ vs control (C). 

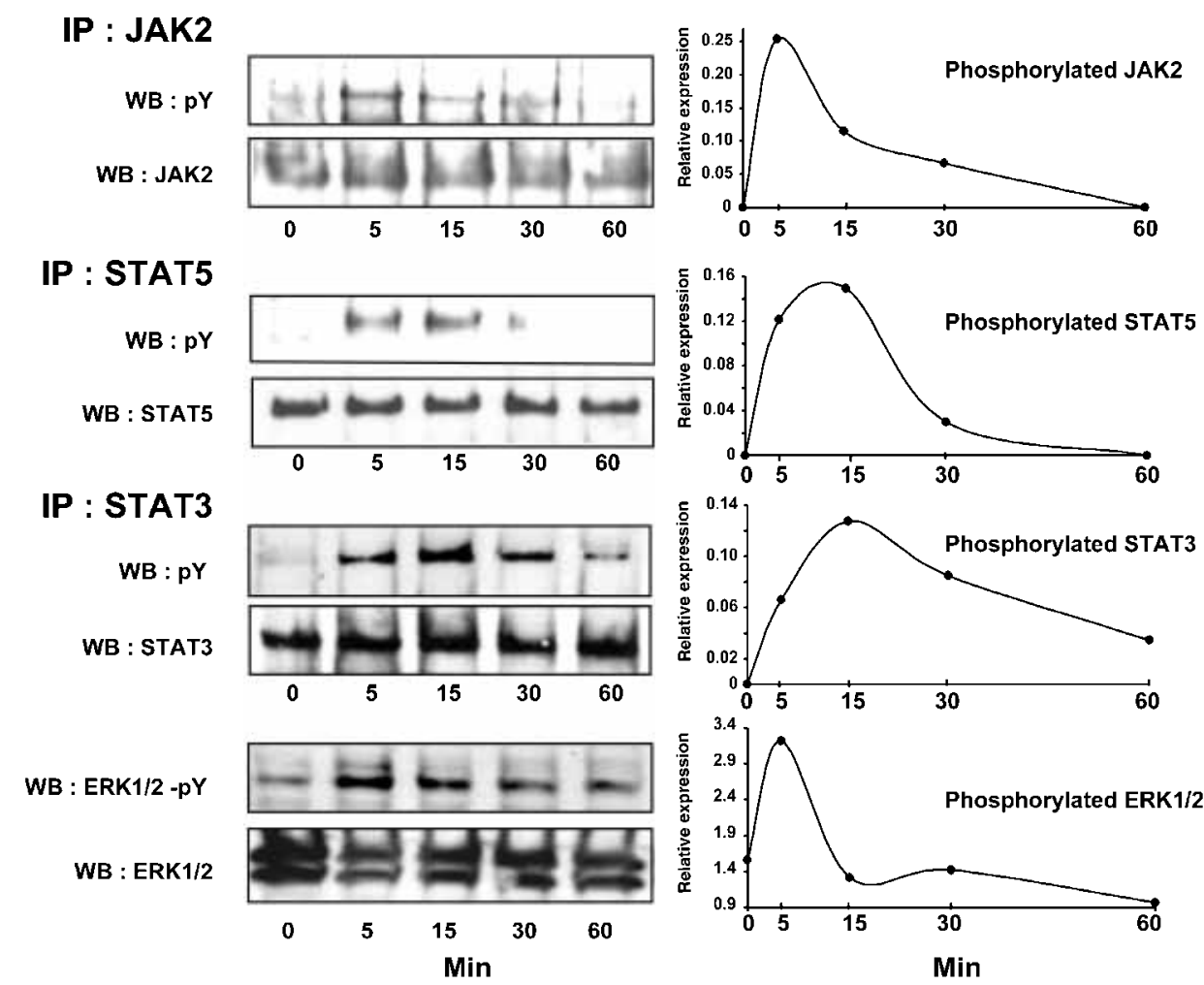

Figure 3 Activation of JAK/STAT and MAP kinase pathways by PRL. Fully differentiated T37i cells were starved for $18 \mathrm{~h}$ in minimum medium containing $100 \mathrm{nM}$ insulin and $2 \mathrm{nM}$ T3, then were stimulated with $100 \mathrm{ng} / \mathrm{ml} \mathrm{PRL}$ for 0-60 min. Control cells corresponded to the mock-treated cells. Protein lysates prepared at indicated time were subjected to immunoprecipitation (IP) with specific antibodies for JAK2, STAT5 or STAT3. Samples were submitted to a SDS-PAGE and Western blotting (WB) analysis using a phospho-tyrosine ( $\mathrm{pY}$ ) antibody. For the MAP kinase pathway, direct Western blotting was performed with polyclonal anti-MAP kinase (ERK1/2) and monoclonal anti-MAP kinase phosphotyrosine (pY) antibodies, clone 12D4 (ERK1/2-pY). A representative blot of at least three independent experiments is presented. Quantifications were performed as described in the Materials and methods section.

higher in the BAT of $\mathrm{PRLR}^{-/-}$pups than in wild-type animals (Fig. 7B). Accordingly, we observed a heterozygous phenotype since leptin content was intermediate in the BAT of $\mathrm{PRLR}^{+/-}$ mice, this level of leptin content being significantly 2-fold higher than that measured in BAT of control animals. Altogether, our findings provide additional support for the involvement of PRL signaling pathway in the biosynthesis, the secretion and/or the release of leptin by the BAT in vivo.

\section{Discussion}

At the end of fetal life, brown adipocytes differentiate on the basis of an adipogenic activation cascade related to the expression of a set of lipogenic enzymes resulting in the appearance of a multilocular fat droplets phenotype as well as a thermogenic program leading to UCP1 expression, which prevents newborns from hypothermia through the nonshivering thermogenesis mechanism (Ricquier \& Bouillaud 2000, Rosen \& Spiegelman 2000).

Here, we provide the first evidence that PRLRs are present at both mRNA and protein levels and functional in differentiated T37i cells and in BAT of newborn mice. Interestingly, we demonstrated that PRLR transcripts exhibit a short half-life and are up-regulated by insulin and T3, consistent with their appearance during the brown adipocyte 


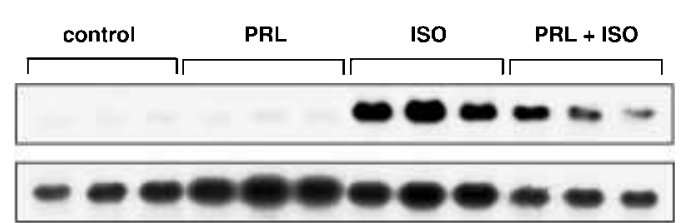

UCP1

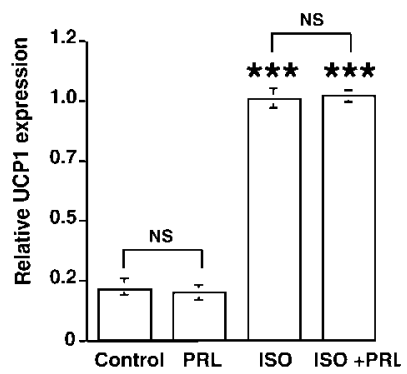

Figure $4 \mathrm{UCP} 1$ transcription is not regulated by $P R L$ in T37i cells. Isoproterenol (ISO)-stimulated expression of UCP1 transcripts. Differentiated T37i cells were starved for $18 \mathrm{~h}$ in minimum medium containing $100 \mathrm{nM}$ insulin and $2 \mathrm{nM} \mathrm{T3}$, then stimulated for $6 \mathrm{~h}$ with or without $100 \mathrm{ng} / \mathrm{ml} \mathrm{PRL}, 1 \mu \mathrm{M}$ isoproterenol, or with both. Control cells corresponded to the mock-treated cells. Northern blottings were performed with specific probes for UCP1 and GAPDH. Signals were quantified by Instantlmager. Results expressed as UCP1/GAPDH ratio represent means \pm S.E.M. of six independent determinations. NS, not significant. ${ }^{* \star *} P<0.001$ vs control.

differentiation program. This is in accord with what has already been shown in the white adipocyte 3T3-L1 cell line during preadipocyte differentiation (McAveney et al. 1996) and with the presence of PRLRs in mouse white adipose tissue (Ling et al. 2000).

We further demonstrated that PRL activates STAT5 in brown adipocytes, a result consistent with previous results, which reported the involvement of PRLRs in the white adipocyte differentiation program via STAT5 (Nanbu-Wakao et al. 2000, 2002). In addition to activation of the JAK2/STAT5 pathway, we showed that STAT3 is also a downstream effector of PRL in brown adipocytes, as already described in T47D cells (Llovera et al. 2000) and in mouse mammary epithelial cells (DaSilva et al. 1996, Chapman et al. 1999). These results suggest that PRL-mediated STAT3 activation may modulate the transcription of a subset of tissue-specific genes that remains to be determined.

To investigate the biological action of PRL in brown adipocytes, we studied the signal transduction pathways leading to expression of UCP1 and leptin. We first showed that PRL alone was not

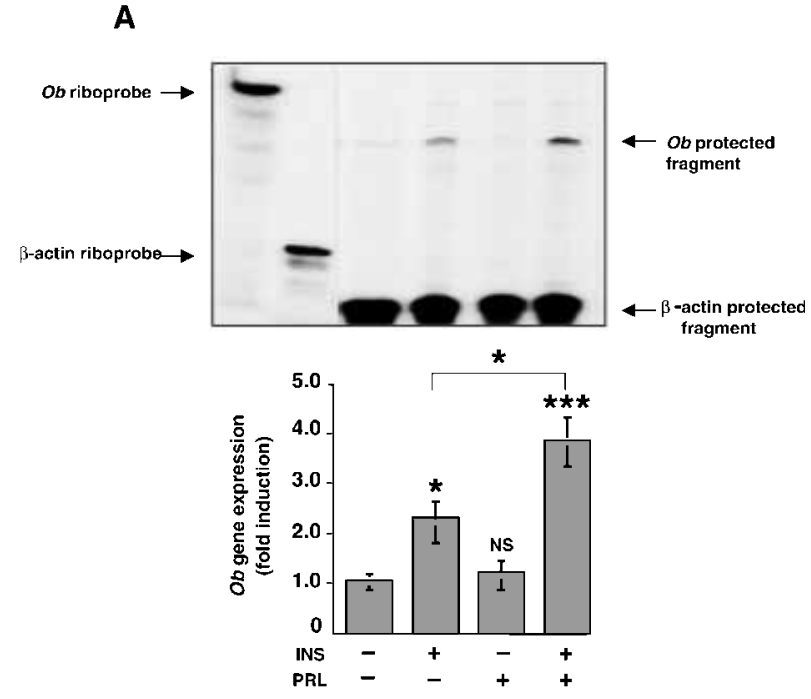

B

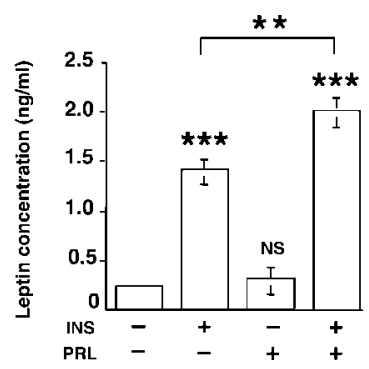

Figure 5 PRL potentiates the stimulatory effect of insulin on leptin expression and release.

(A) Differentiated T37i cells were starved for $18 \mathrm{~h}$ in minimum medium containing $100 \mathrm{nM}$ insulin then were stimulated for $2 \mathrm{~h}$ with or without $20 \mathrm{nM}$ insulin, $100 \mathrm{ng} / \mathrm{ml} \mathrm{PRL}$ or with both. RPA were performed with $O b$ and $\beta$-actin probes. Signals were quantified and $O b / \beta$-actin ratio was calculated. Results were expressed as fold induction of $O b$ gene expression and represented means \pm S.E.M. of 7-11 independent determinations. NS, not significant; ${ }^{\star} P<0.05$; ${ }^{\star \star \star} P<0.001$ vs control. (B) Measurement of leptin concentration released in the culture medium.

Differentiated T37i cells were starved for $8 \mathrm{~h}$ in minimum medium and then stimulated for $18 \mathrm{~h}$ with or without $20 \mathrm{nM}$ insulin, $100 \mathrm{ng} / \mathrm{ml}$ PRL or with both. Leptin concentrations quantified by RIA are expressed in $\mathrm{ng} / \mathrm{ml}$ of culture medium. Results represent means \pm S.E.M. of 12 determinations. NS, not significant; ${ }^{\star \star} P<0.01$; ${ }^{* \star \star} P<0.001$ vs control.

able to induce UCP1 expression in T37i cells nor was it able to modulate catecholamine- and retinoic acid-stimulated UCP1 expression. In accord with these findings, we were unable to detect any significant change in UCP1 content in the BAT of PRLR knockout mice, indicating that UCP1 is not 

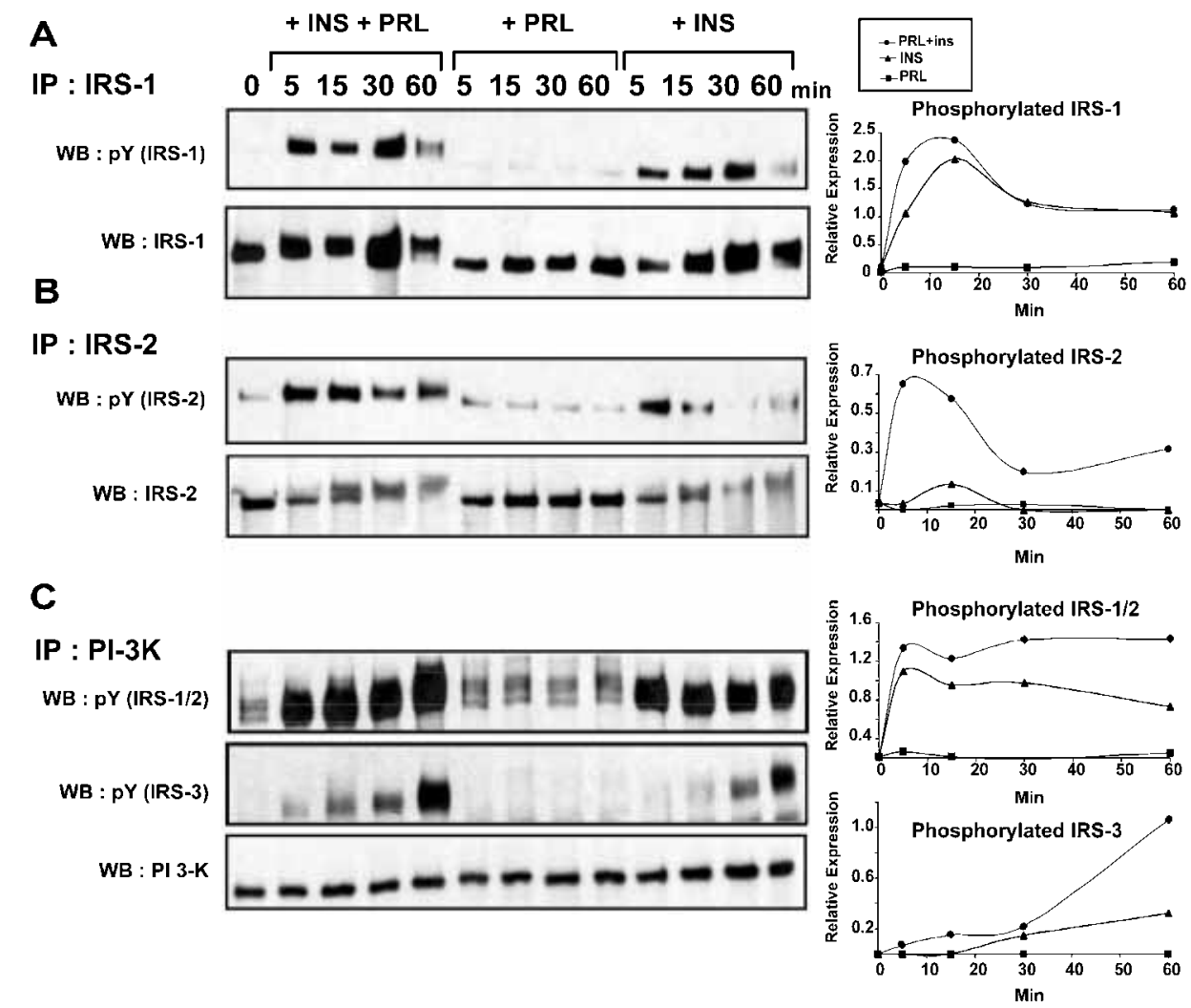

Figure 6 Activation of insulin signaling pathway is enhanced by PRL. (A-C) Differentiated T37i cells were starved for $18 \mathrm{~h}$ in minimum medium containing $2 \mathrm{nM}$ T3, then were stimulated with $100 \mathrm{ng} / \mathrm{ml}$ PRL, $20 \mathrm{nM}$ insulin or both hormones during 0-60 min. Protein lysates were subjected to immunoprecipitation (IP) with specific antibodies for IRS-1, IRS-2 or PI 3-kinase. Samples were analyzed by Western blot (WB) using anti-phospho-tyrosine (pY) antibodies. A representative blot of at least two independent experiments is presented.

a direct target of PRL but rather should be regulated mostly by a sympathetic pathway. However, we cannot exclude that in vivo PRL might modulate UCP1 expression, which also depends on the hormonal and metabolic environment in a developmental-stage manner (Pearce et al. 2003, Xiao et al. 2004).

We have previously shown that insulin is an important stimulator of leptin synthesis in brown adipocytes and exerts its effect through a strong, rapid and transient activation of transcription (Buyse et al. 2001). We have now demonstrated that $\mathrm{Ob}$ gene expression as well as leptin release from differentiated T37i cells is greatly potentiated by the addition of PRL only in the presence of insulin, indicating the necessity for a concomitant activation of both hormone signaling pathways. We next addressed the question of the molecular mechanisms by which PRL potentiates insulin effects. On the one hand, PRL alone failed to induce tyrosine phosphorylation of IRS in the brown adipocyte T37i cell model, a result which contrasts with those obtained in PRLRoverexpressing cells in which IRS-1, -2 and -3 were tyrosine phosphorylated by PRL (Berlanga et al. 1997, Yamauchi et al. 1998). This indicated that in vitro PRL responsiveness largely depends on the level of PRLR expression and/or its downstream effectors. On the other hand, we clearly demonstrated that the IRS/PI 3-kinase pathway is overstimulated after PRL incubation. Indeed, we showed that PRL potentiates insulin-stimulated phosphorylation of IRS-1, -2 and -3 and their association with p85 PI 3-kinase. These results confirm the essential role played by IRS-1 through PI 3-kinase signaling pathway in inducing 
A
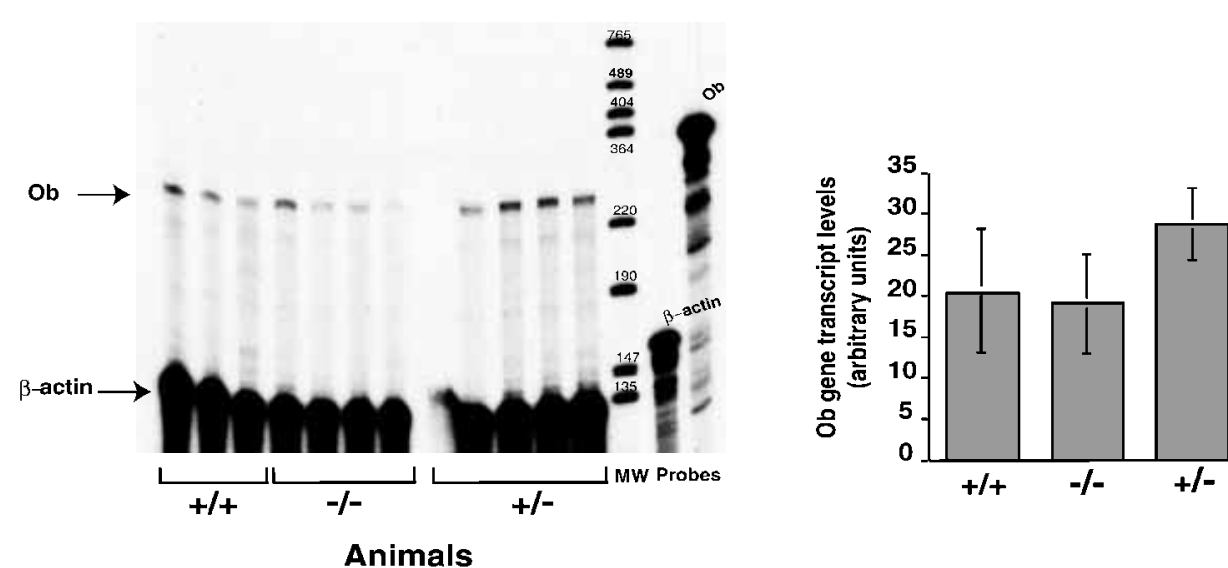

B

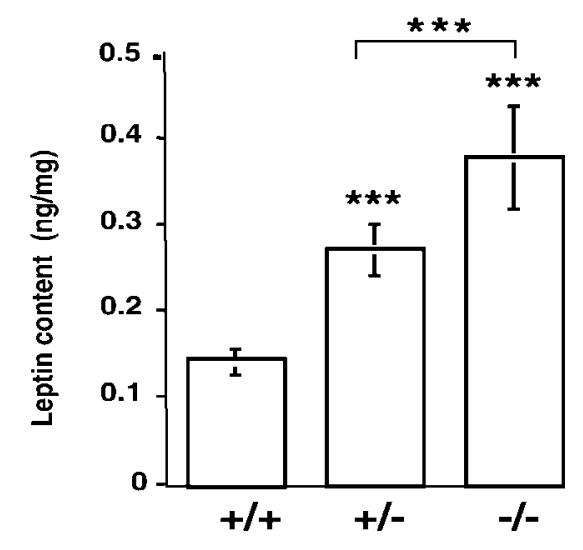

Animals

Figure 7 Leptin content is increased in the BAT of PRLR-null mice. (A) Analysis of Ob gene expression by RPA. BAT was isolated from 2-week-old wild-type, PRLR+/and PRLR-null mice. RPA were performed using specific probes for $O b$ and $\beta$-actin. Signals were quantified and $O b / \beta$-actin ratio was calculated. Results are expressed as arbitrary units and represent means \pm S.E.M. of 3-11 mice. MW: molecular weight.

(B) Measurement of leptin concentration by RIA. BAT isolated from 2-week-old wild-type, $\mathrm{PRLR}^{+/-}$and PRLR-null mice was homogenized and leptin content quantified by RIA was expressed in $\mathrm{ng} / \mathrm{mg}$ of protein. Results represent means \pm S.E.M. of $11-14$ individual animals. ${ }^{* * *} P<0.001$ vs control.

adipogenic and thermogenic gene expression upon insulin or insulin-like growth factor stimulation, already demonstrated in primary brown adipocytes (Valverde et al. 1997, 1999, Teruel et al. 1998, Mur et al. 2003). The role of IRS-1, -2 and -3 in PRL signaling is to be phosphorylated by JAK2, thereby providing docking sites for p85 PI 3-kinase and activating PI 3-kinase (Yamauchi et al. 1998). It has also been shown that the expression of dominant negative JAK2 almost completely abolished PRLinduced phosphorylation of IRS-1 and -2, and their association with PI 3-kinase (Yamauchi et al. 1998). Finally, we suggest that PRL acts as an insulin sensitizer in brown fat, consistent with previous work performed in white adipocytes which showed that PRL, in combination with insulin, induces CIS 
and SOCS 3 mRNA expression, two known PRL targets (Ling \& Billig 2001).

This work, which demonstrates that BAT is a novel PRL target tissue, constitutes the initial step of a detailed in vivo study of the PRL signaling pathway. PRL is best known as a lactogenic hormone responsible for the development of the mammary gland, but it also plays a crucial role in reproduction, although many other functions, most notably affecting adipose tissues, are reported (Bole-Feysot et al. 1998, Flint et al. 2003). Thus, the availability of PRLR knockout model allowed us to analyze brown adipocyte gene expression. In accord with the potentiating effect of PRL on insulin-stimulated leptin secretion observed in the T37i cell model, we demonstrated that the absence of PRL signaling curtailed leptin release from brown adipocytes as evidenced by the significant increase in leptin content in BAT of null animals. To the best of our knowledge, this is the first evidence that PRL can affect leptin production from brown fat. There are, however, several conflicting reports about the effect of PRL on leptin release from white adipose tissue. Although it has been recently proposed that PRL suppressed insulin-induced leptin secretion from cultured white adipocytes (Ling \& Billig 2001), most studies indicated that in vivo PRL stimulates leptin release notably in transgenic female mice overexpressing PRL (Ling \& Billig 2001) but also in rats treated with exogenous PRL (Gualillo et al. 1999) or with lipopolysaccharide, leading to an endogenous PRL secretion (Mastronardi et al. 2001). Furthermore, old PRLR-deficient female mice exhibited a progressive decrease in white adipose tissue mass (Freemark et al. 2001), concomitant with a reduction of circulating leptin levels. The significance of this PRL effect on leptin secretion remains to be elucidated but it is clear from our results that, since no change in $O b$ mRNA steady state levels was observed in mouse models, PRL is not directly involved in transcription rate, but more likely in the secretion or release process of leptin in vivo. Altogether, these data point toward a stimulatory action of PRL on leptin secretion in BAT. Of interest, it has been proposed that white adipose tissue is not functional at birth, suggesting that brown adipocyte-secreted leptin may represent the predominant if not exclusive source of leptin during this critical perinatal period (Dessolin et al. 1997). Therefore, we propose that leptin secreted by brown adipocytes may have an important physiological role in terms of food intake control, thermogenesis and metabolic characteristics (Yuen et al. 2003), presumably through endocrine and/or autocrine mechanisms that remain to be established.

In summary, we have shown that brown adipocytes express functional PRLRs. We have provided evidence for a cross-talk between PRL and the insulin signaling pathway in brown adipocytes and further demonstrated that PRL potentiates insulin-stimulated secretion and/or release of leptin by BAT. Our findings provide the basis to further investigate the role of PRL and its receptor in brown adipocyte differentiation and function.

\section{Acknowledgements}

We are indebted to Dr V Goffin (INSERM U584, Paris, France) for providing human PRL and Dr D Linzer (Northwestern University, Evanston, IL, USA) for the gift of the mouse PRLR cDNA. We also thank Dr F Talamantes (University of California, Santa Cruz, CA, USA) for the anti-PRLR polyclonal antibody. Dr L Pascual-Le Tallec (INSERM U478, Paris, France) is also acknowledged for helpful discussion.

\section{References}

Berlanga JJ, Gualillo O, Buteau H, Applanat M, Kelly PA \& Edery M 1997 Prolactin activates tyrosyl phosphorylation of insulin receptor substrate-1 and phosphatidylinositol-3-OH kinase. Fournal of Biological Chemistry 272 2050-2052.

Binart N, Helloco C, Ormandy CJ, Barra J, Clement-Lacroix P, Baran N \& Kelly PA 2000 Rescue of preimplantatory egg development and embryo implantation in prolactin receptor-deficient mice after progesterone administration. Endocrinology 141 2691-2697.

Bole-Feysot C, Goffin V, Edery M, Binart N \& Kelly PA 1998 Prolactin and its receptor: actions, signal transduction pathways and phenotypes observed in prolactin receptor knockout mice. Endocrine Reviews 19 225-268.

Budge H, Mostyn A, Wilson V, Khong A, Walker AM, Symonds ME \& Stephenson T 2002 The effect of maternal prolactin infusion during pregnancy on fetal adipose tissue development. Journal of Endocrinology 174 427-433.

Buyse M, Viengchareun S, Bado A \& Lombes M 2001 Insulin and glucocorticoids differentially regulate leptin transcription and secretion in brown adipocytes. FASEB fournal 15 1357-1366.

Chapman RS, Lourenco PC, Tonner E, Flint DJ, Selbert S, Takeda K, Akira S, Clarke AR \& Watson CJ 1999 Suppression of epithelial apoptosis and delayed mammary gland involution in mice with a conditional knockout of Stat3. Genes and Development 13 $2604-2616$ 
DaSilva L, Rui H, Erwin RA, Zack H, Kirken RA, Malabarba MG, Hackett RH, Larner AC \& Farrar WL 1996 Prolactin recruits STAT1, STAT3 and STAT5 independent of conserved receptor tyrosines TYR 402, TYR 479, TYR 515 and TYR 580. Molecular and Cellular Endocrinology 117 131-140.

Dessolin S, Schalling M, Champigny O, Lonnqvist F, Ailhaud G, Dani C \& Ricquier D 1997 Leptin gene is expressed in rat brown adipose tissue at birth. FASEB Foumal 11 382-387.

Flint DJ, Binart N, Kopchick J \& Kelly P 2003 Effects of growth hormone and prolactin on adipose tissue development and function. Pituitary 6 97-102.

Freemark M, Fleenor D, Driscoll P, Binart N \& Kelly PA 2001 Body weight and fat deposition in prolactin receptor-deficient mice. Endocrinology 142 532-537.

Goffin V, Kinet S, Ferrag F, Binart N, Martial JA \& Kelly PA 1996 Antagonistic properties of human prolactin analogs that show paradoxical agonistic activity in the $\mathrm{Nb} 2$ bioassay. Fournal of Biological Chemistry 271 16573-16579.

Goffin V, Binart N, Touraine P \& Kelly PA 2002 Prolactin: the new biology of an old hormone. Annual Review of Physiology 64 47-67.

Grosdemouge I, Bachelot A, Lucas A, Baran N, Kelly PA \& Binart N 2003 Effects of deletion of the prolactin receptor on ovarian gene expression. Reproductive Biology and Endocrinology 1 1-12.

Gualillo O, Lago F, Garcia M, Menendez C, Senaris R, Casanueva FF \& Dieguez C 1999 Prolactin stimulates leptin secretion by rat white adipose tissue. Endocrinology 140 5149-5153.

Ling C \& Billig H 2001 PRL receptor-mediated effects in female mouse adipocytes: PRL induces suppressors of cytokine signaling expression and suppresses insulin-induced leptin production in adipocytes in vitro. Endocrinology 142 4880-4890.

Ling C, Hellgren G, Gebre-Medhin M, Dillner K, Wennbo H, Carlsson B \& Billig H 2000 Prolactin (PRL) receptor gene expression in mouse adipose tissue: increases during lactation and in PRL-transgenic mice. Endocrinology 141 3564-3572.

Llovera M, Pichard C, Bernichtein S, Jeay S, Touraine P, Kelly PA \& Goffin V 2000 Human prolactin (hPRL) antagonists inhibit hPRL-activated signaling pathways involved in breast cancer cell proliferation. Oncogene 19 4695-4705.

Maniatis T, Fritsch EF \& Sambrook J 1982 Molecular Cloning: a Laboratory Manual, edn 1. New York: Cold Spring Harbor Laboratory Press.

Mastronardi CA, Yu WH, Srivastava VK, Dees WL \& McCann SM 2001 Lipopolysaccharide-induced leptin release is neurally controlled. PNAS 98 14720-14725.

McAveney KM, Gimble JM \& Yu-Lee L 1996 Prolactin receptor expression during adipocyte differentiation of bone marrow stroma. Endocrinology 137 5723-5726.

Mur C, Arribas M, Benito M \& Valverde AM 2003 Essential role of insulin-like growth factor I receptor in insulin-induced fetal brown adipocyte differentiation. Endocrinology 144 581-593.

Nanbu-Wakao R, Fujitani Y, Masuho Y, Muramatu M \& Wakao H 2000 Prolactin enhances CCAAT enhancer-binding protein-beta (C/EBP beta) and peroxisome proliferator-activated receptor gamma (PPAR gamma) messenger RNA expression and stimulates adipogenic conversion of NIH-3T3 cells. Molecular Endocrinology 14 307-316.

Nanbu-Wakao R, Morikawa Y, Matsumura I, Masuho Y, Muramatsu MA, Senba E \& Wakao H 2002 Stimulation of 3T3-L1 adipogenesis by signal transducer and activator of transcription 5. Molecular Endocrinology 16 1565-1576.
Ormandy CJ, Camus A, Barra J, Damotte D, Lucas BK, Buteau H, Edery M, Brousse N, Babinet C, Binart N et al. 1997 Null mutation of the prolactin receptor gene produces multiple reproductive defects in the mouse. Genes and Development $\mathbf{1 1}$ $167-178$.

Pearce S, Dieguez G, Gualillo O, Symonds ME \& Stephenson T 2003 Differential effects of age and sex on the postnatal responsiveness of brown adipose tissue to prolactin administration in rats. Experimental Physiology 88 527-531.

Penfornis P, Viengchareun S, Le Menuet D, Cluzeaud F, Zennaro MC \& Lombes M 2000 The mineralocorticoid receptor mediates aldosterone-induced differentiation of T37i cells into brown adipocytes. American Journal of Physiology. Endocrinology and Metabolism 279 E386-E394.

Ricquier D \& Bouillaud F 2000 Mitochondrial uncoupling proteins: from mitochondria to the regulation of energy balance. Fournal of Physiology 529 3-10.

Rosen ED \& Spiegelman BM 2000 Molecular regulation of adipogenesis. Annual Review of Cell and Developmental Biology 16 $145-171$.

Royster M, Driscoll P, Kelly PA \& Freemark M 1995 The prolactin receptor in the fetal rat: cellular localization of messenger RNA, immunoreactive protein, and ligand binding activity and induction of expression in late gestation. Endocrinology 136 3892-3900.

Teruel T, Valverde AM, Navarro P, Benito M \& Lorenzo M 1998 Inhibition of PI 3-kinase and RAS blocks IGF-I and insulin-induced uncoupling protein 1 gene expression in brown adipocytes. Fournal of Cellular Physiology 176 99-109.

Valverde AM, Lorenzo M, Navarro P \& Benito M 1997 Phosphatidylinositol 3-kinase is a requirement for insulin-like growth factor I-induced differentiation, but not for mitogenesis, in fetal brown adipocytes. Molecular Endocrinology 11 595-607.

Valverde AM, Kahn CR \& Benito M 1999 Insulin signaling in insulin receptor substrate (IRS)-1-deficient brown adipocytes: requirement of IRS-1 for lipid synthesis. Diabetes $\mathbf{4 8} 2122-2131$.

Viengchareun S, Zennaro MC, Pascual-Le Tallec L \& Lombes M 2002 Brown adipocytes are novel sites of expression and regulation of adiponectin and resistin. FEBS Letters 532 345-350.

Xiao XQ, Grove KL, Grayson BE \& Smith MS 2004 Inhibition of uncoupling protein expression during lactation: role of leptin. Endocrinology $145830-838$.

Yamauchi T, Kaburagi Y, Ueki K, Tsuji Y, Stark GR, Kerr IM, Tsushima T, Akanuma Y, Komuro I, Tobe K et al. 1998 Growth hormone and prolactin stimulate tyrosine phosphorylation of insulin receptor substrate-1, -2 , and -3 , their association with p85 phosphatidylinositol 3-kinase (PI3-kinase), and concomitantly PI3-kinase activation via JAK2 kinase. Fournal of Biological Chemistry 273 15719-15726.

Yuen BS, Owens PC, Muhlhausler BS, Roberts CT, Symonds ME, Keisler DH, McFarlane JR, Kauter KG, Evens Y \& McMillen IC 2003 Leptin alters the structural and functional characteristics of adipose tissue before birth. FASEB fournal 17 1102-1104.

Zennaro MC, Le Menuet D, Viengchareun S, Walker F, Ricquier D \& Lombes M 1998 Hibernoma development in transgenic mice identifies brown adipose tissue as a novel target of aldosterone action. Fournal of Clinical Investigation 101 1254-1260.

Received 9 June 2004 Accepted 27 August 2004 